\title{
Co(II) OPTICAL ABSORPTION IN SPINELS: INFRARED AND LIGAND-FIELD SPECTROSCOPIC STUDY OF THE IONICITY OF THE BOND. MAGNETIC STRUCTURE AND $\mathrm{Co}^{2+} \rightarrow \mathrm{Fe}^{3+}$ MMCT IN FERRITES. CORRELATION WITH THE MAGNETO-OPTICAL PROPERTIES
}

\author{
F. HOCHU ${ }^{\mathrm{a}, \mathrm{b}}$ and M. LENGLET ${ }^{\mathrm{b}, \dagger}$ \\ ${ }^{a}$ ENSTIMD, 941 Rue C. Bourseul, BP 838, 59508 Douai Cedex, France; \\ ${ }^{\mathrm{b}}$ Laboratorie d'Analyse de Spectroscopie et de Traitement de Surface des \\ Matériaux, Université de Rouen, IUT, 76821 Mont saint Aignan Cedex, France
}

(Received 13 February 1997; In final form of 13 March 1997)

\begin{abstract}
The analysis of the infrared and ligand field spectra of $\mathrm{CoM}_{2} \mathrm{O}_{4}$ spinels reveals that the ionicity of these compounds varies in the following order aluminate $>$ gallate $>$ ferrite and chromite $>$ rhodite and cobaltite. A linear relation has been established between the $\Delta(\text { LO-TO })_{1}$ splitting, Racah parameter and the ionic-covalent parameter $S_{\mathrm{Sp}}=\Sigma I C P_{\text {tetra }}+\sum I C P_{\text {octa }}$. The influence of strong superexchange interactions on the optical spectrum of cobalt ferrites has been studied. The cation distribution has been established by EXAFS and XANES measurements. The cluster $\left(\mathrm{CoFeO}_{10}\right)^{15-}$ is characterized by a large MMCT transition $\mathrm{Co}^{2+} \rightarrow \mathrm{Fe}^{3+}$ at $1.65-1.7 \mathrm{eV}$ (FWMH: $1.35-1.95 \mathrm{eV})$. The ${ }^{4} A_{2} \rightarrow{ }^{4} T_{1}(\mathrm{P})$ tetrahedral cobalt(II) in ferrimagnetic compounds is overlapped by the MMCT band. This study and the reinvestigation of the iron(III) electronic spectrum is ferrites may explain the magneto-optical properties of mixed cobalt-ferrites.
\end{abstract}

Keywords: Cobalt ferrites; optical properties; magneto-optical effect

${ }^{\dagger}$ To whom correspondence should be addressed. 


\section{INTRODUCTION}

Application of cobalt ferrite as high density magneto-optical recording media has been demonstrated since about 15 years. Nevertheless, the interpretation of the Faraday rotation spectra remains uncertain. Consequently, in this paper, we present a reinvestigation of the vibrational and optical properties of cobalt(II) spinels in correlation with a new parameter introduced by Portier et al. [1]: the ioniccovalent parameter of cations based on polarizing power and electronegativity (this parameter accounts for the iono-covalent nature of chemical bonds permitting coherent interpretation of electronic properties). Another purpose of this paper is the study of the influence of superexchange interactions on the optical spectra of substituted cobalt(II) ferrites and more precisely on the $\mathrm{Co}^{2+} \rightarrow \mathrm{Fe}^{3+}$ metalmetal charge transfer (MMCT) located at $1.7 \mathrm{eV}$. The compounds chosen to illustrate the optical properties of the $\left(\mathrm{CoFeO}_{10}\right)^{15-}$ cluster belong to the $\mathrm{CoFe}_{2-x} \mathrm{Ga}_{x} \mathrm{O}_{4}$ system. The cation distribution is deduced from EXAFS and XANES measurements. The analysis of the iron(III) electronic spectra in ferrimagnetic spinels like $\mathrm{MgFe}_{2} \mathrm{O}_{4}$ and $\mathrm{Li}_{0.5} \mathrm{Fe}_{2.5} \mathrm{O}_{4}$ and the study of the optical properties of $\mathrm{Co}$ (II) spinels allow a quantitative evaluation of the contribution of both chargetransfer and crystal-field transitions to the magneto-optical properties of different substituted cobalt ferrites in the range $0.5-2.5 \mathrm{eV}$.

\section{EXPERIMENTAL}

Different series of cobalt spinels $\mathrm{CoFe}_{2-x} \mathrm{Ga}_{x} \mathrm{O}_{4}, \mathrm{CoFe}_{2-x} \mathrm{Cr}_{x} \mathrm{O}_{4}$ and $\mathrm{CoGa}_{2-x} \mathrm{Cr}_{x} \mathrm{O}_{4}$ were prepared by means of a simple ceramic method by mixing suitable proportions of $\mathrm{CoCO}_{3}$ and mixtures of appropriate trivalent oxides and twofold sintering at $800^{\circ} \mathrm{C}$ and $1100^{\circ} \mathrm{C}$. in air atmosphere. The samples slowly cooled at $10^{\circ} \mathrm{C} \cdot \mathrm{hr}^{-1}$ were checked by $\mathrm{X}$-ray diffraction. X-ray absorption spectra of polycrystalline samples have been recorded at room temperature using the radiation emitted at the DCI synchrotron (LURE, Orsay, France) running at $1.85 \mathrm{GeV}$. For the data collection which has been performed in transmission mode over $6900-7900 \mathrm{eV}$ and $7500-8500 \mathrm{eV}$, respectively for Fe and Co absorptions, the white radiation was monochromatized by the 
EXAFS IV double crystal (Si 311) spectrophotometer working in the stepping mode $(0.25 \mathrm{eV}$ for XANES and $2 \mathrm{eV}$ for EXAFS). The coordination of cobalt may be determined by measuring the intensity of the pre-edge peak on normalized XANES spectra.

UV-Vis-NIR diffuse reflectance spectra were obtained using a Perkin-Elmer lambda 9 spectrophotometer equipped with an integrating sphere accessory and a 7300 computer. The spectra are expressed in absorbance or converted to the Kubelka-Munk remission function.

The calculated infrared phonon modes for II-III cobalt spinels have been determined by Kramers-Kronig analysis of the transmission spectra using a method previously published [2]. The crystallographic data and cation distribution are listed in Table I. EXAFS measurements of the $\mathrm{Co}^{2+}-\mathrm{O}^{2-}$ distances in $A$ and $B$ sites confirms the deviation from Vegard's relationship observed by Lensen [3] for the variation of the lattice parameter with increasing gallium content in the $\mathrm{CoFe}_{2-x} \mathrm{Ga}_{x} \mathrm{O}_{4}$ system. In ferrimagnetic compounds $(x<1), \mathrm{Ga}^{3+}$ ions show a marked $\mathrm{Td}$ site preference.

TABLE I Crystallographic data and cation repartition from EXAFS and XANES measurements

\begin{tabular}{|c|c|c|c|c|c|c|c|c|c|}
\hline \multicolumn{7}{|c|}{ Co K-edge } & \multicolumn{3}{|c|}{ Fe K-edge } \\
\hline \multicolumn{10}{|c|}{ System $\mathrm{CoFe}_{2-x} \mathrm{Ga}_{x} \mathrm{O}_{4}$} \\
\hline$x$ & $\begin{array}{c}d_{A} \\
(\mathrm{~nm})\end{array}$ & $\begin{array}{c}d_{B} \\
(\mathrm{~nm})\end{array}$ & (a) & $\begin{array}{c}\% \mathrm{Co} \\
\text { (b) }\end{array}$ & $\begin{array}{l}\text { in } \mathrm{Td} \\
\text { (c) }\end{array}$ & $(d)^{*}$ & $\begin{array}{c}d_{A} \\
(\mathrm{~nm})\end{array}$ & $\begin{array}{c}d_{B} \\
(\mathrm{~nm})\end{array}$ & $\% \mathrm{Fe}$ in $\mathrm{Td}$ \\
\hline 0 & 0.194 & 0.203 & & 20 & & $6-8$ & 0.190 & 0.199 & 40 \\
\hline 0.5 & 0.196 & 0.205 & & $10-20$ & & & 0.190 & 0.199 & 40 \\
\hline 1 & 0.192 & 0.204 & 13 & 20 & & & 0.192 & 0.200 & 50 \\
\hline 1.4 & 0.192 & 0.205 & 20 & 20 & 30 & & 0.192 & 0.202 & 50 \\
\hline 2 & 0.190 & 0.202 & 30 & 25 & 30 & & & & \\
\hline \multicolumn{10}{|c|}{ System $\mathrm{CoFe}_{2-x} \mathrm{Cr}_{x} \mathrm{O}_{4}$} \\
\hline 0.8 & 0.196 & 0.204 & & 65 & & & 0.195 & 0.201 & 30 \\
\hline \multicolumn{10}{|c|}{ System $\mathrm{CoGa}_{2-x} \mathrm{Cr}_{x} \mathrm{O}_{4}$} \\
\hline 0.5 & 0.196 & & & 45 & 50 & & & & \\
\hline 1 & 0.196 & 0.204 & 75 & 75 & 72 & & & & \\
\hline 1.5 & 0.198 & 0.206 & 87 & 90 & 95 & & & & \\
\hline 2 & 0.198 & & & 100 & & & & & \\
\hline
\end{tabular}

$\mathrm{Co}^{2+} \%$ in tetrahedral coordination issued from (a) XANES, (b) EXAFS, (c) optical absorption at $6500 \mathrm{~cm}^{-1}$ and (d) neutron diffraction or Mössbauer measurement.

*references in Landolt-Börnstein, III $12 \mathrm{~b}$ and III $27 \mathrm{~d} . \mathrm{Fe}^{3+} \%$ in tetrahedral coordination from EXAFS measurements. 


\section{RESULTS AND INTERPRETATION}

\subsection{Spectroscopic Study of the Ionicity of Cobalt(II) Spinels}

The ground state of tetrahedrally coordinated $\mathrm{Co}^{2+}$ is ${ }^{4} A_{2}$ and there are three excited quartet states ${ }^{4} T_{2}(F),{ }^{4} T_{1}(F)$ and ${ }^{4} T_{1}(P)$. In the absence of spin-orbit coupling only the ${ }^{4} A_{2} \rightarrow{ }^{4} T_{1}$ transitions are allowed and these dominate the absorption spectrum.

The optical absorption of tetrahedral cobalt(II) in spinel-type oxides has been reinvestigated in order to analyze the relationship between the ionic-covalent parameter ICP and the Racah $B$ value. An assignment of peak positions is presented in Table II. The bandwidths observed for the two-low energy transitions are large and may be accounted for by spin orbit coupling (theoretically, to first order, $4 \lambda$ and $6 \lambda$ for ${ }^{4} T_{2}$ and $\left.{ }^{4} T_{1}\left({ }^{4} F\right)\right)$. Low temperature studies suggest that low symmetry fields and vibrational structure may contribute to the band widening $[4,5]$. Moreover in the visible region there are many spin forbidden quartet-doublet transitions which can gain intensity by interaction with the spin allowed band. For computational purposes, the transition energies to calculate $D_{q}$ and $B$, are based on the centers of intensity of these bands. The spin-orbit coupling constant has been calculated from the ${ }^{4} T_{1}\left({ }^{4} F\right)$ band: the values obtained are similar to those reported previously.

\begin{tabular}{lccccc}
\hline & \multicolumn{3}{c}{${ }^{4} A_{2} \rightarrow{ }^{4} T_{1}\left({ }^{4} \mathrm{~F}\right)$} & $\lambda\left(\mathrm{cm}^{-1}\right)$ & Ref. \\
\hline $\mathrm{Co}^{2+}: \mathrm{ZnO}$ & 6100 & 6950 & 7550 & 210 & 4 \\
$\mathrm{Co}^{2+}: \mathrm{MgAl}_{2} \mathrm{O}_{4}$ & 6450 & 7300 & 8000 & 250 & 6 \\
& 6424 & 7467 & 8070 & 275 & 5 \\
$\mathrm{CoAl}_{2} \mathrm{O}_{4}$ & 6600 & 7450 & 8100 & 250 & \\
$\mathrm{CoGa}_{2} \mathrm{O}_{4}$ & 5950 & 6810 & 7330 & 230 & \\
$\mathrm{CoFe}_{2} \mathrm{O}_{4}$ & 5950 & 6580 & 7140 & 200 & \\
$\mathrm{Co}_{2} \mathrm{TiO}_{4}$ & 5750 & 6580 & 7200 & 240 & \\
\hline
\end{tabular}

The Racah parameter $B$ for a specific ion is well known to vary as a function of the ligands bound to that ion. The value of this parameter is always reduced from that observed with the free spherical ion. The reduction of $B$ has been explained by certain covalency effects, which are called "central-field covalency" and "symmetry restricted covalency" [7]. The first of these is a spherically depressing symmetric effect on the Racah parameter caused by an expansion of the central-ion radial 
TABLE II $\mathrm{Co}^{2+}$ tetrahedral ligand field parameters in spinels

\begin{tabular}{lccccc}
\hline Compound & \multicolumn{5}{c}{ Energy levels $^{\dagger}\left(\mathrm{cm}^{-1}\right)$} \\
& ${ }^{4} A_{2} \rightarrow{ }^{4} T_{1}\left({ }^{4} F\right)^{4} A_{2} \rightarrow{ }^{4} T_{1}\left({ }^{4} P\right)$ & $D_{q}\left(\mathrm{~cm}^{-1}\right)$ & $B$ & $S_{\mathrm{Sp}^{*}}$ \\
\hline $\mathrm{Co}^{2+}: \mathrm{ZnO}$ & 6870 & 16500 & 395 & $\sim 765$ \\
$\mathrm{Co}^{2+}: \mathrm{MgAl}_{2} \mathrm{O}_{4}$ & 7200 & 17200 & 410 & 805 & 3.11 \\
& & & 402 & 815 & \\
$\mathrm{Co}_{0.1} \mathrm{Zn}_{0.9} \mathrm{Al}_{2} \mathrm{O}_{4}$ & 7100 & 17050 & 410 & 790 & 2.73 \\
$\mathrm{CoAl}_{2} \mathrm{O}_{4}$ & 7300 & 17150 & 420 & 790 & 2.66 \\
$\mathrm{Co}_{0.1} \mathrm{Zn}_{0.9} \mathrm{Ga}_{2} \mathrm{O}_{4}$ & 6600 & 16800 & 380 & 805 & 2.45 \\
$\mathrm{CoGa}_{2} \mathrm{O}_{4}$ & 6700 & 16600 & 385 & 785 & 2.39 \\
$\mathrm{CoFe}_{2} \mathrm{O}_{4}$ & 6550 & & 375 & & \\
$\mathrm{Co}_{0.25} \mathrm{Zn}_{0.75} \mathrm{Cr}_{2} \mathrm{O}_{4}$ & 6600 & $\sim 16250$ & 375 & 770 & 2.06 \\
$\mathrm{CoCr}_{2} \mathrm{O}_{4}$ & 6650 & 16250 & 380 & 765 & 2.02 \\
$\mathrm{Co}_{2} \mathrm{TiO}_{4}$ & 6500 & 15700 & 370 & 735 & 2.08 \\
$\mathrm{CoRh}_{2} \mathrm{O}_{4}$ & 6650 & 15400 & 390 & 700 & 1.62 \\
\hline
\end{tabular}

†energy of the barycenter of the three quartet states.

${ }^{*} S_{\mathrm{Sp}}=\Sigma I C P_{\text {tetra }}+\Sigma I C P_{\text {octa }}$.

functions as the consequence of a lower effective charge compared to the ionic charge of the free ion. The second one takes into account the additional effect that the $e_{g}$ and $t_{2 g}$-electrons are not exclusively $d$ character but contain ligand contributions. Because the $e_{g}$-orbitals are $\sigma$-antibonding and the $t_{2 g}$-orbitals only $\pi$-antibonding, different depressing effects on the interelectronic repulsion parameters are to be expected depending on the specific electronic configuration $t_{2 g}^{m} e_{g}^{n}$.

When, for a given cation, ligands are ordered according to the value of $B$ in the corresponding complex, one obtains the nephelauxetic series. Expressed in terms of donor atoms, this series is approximately in order of the polarisability of the ligand atom. If the ligand is maintained constant a nephelauxetic series of metal ions can be established. This will vary according to the polarizing power of cations. The value of $B$, for a given metal and ligand, tends to decrease with decreasing coordination number, i.e., with a decrease in metalligand bond length and a concomitant increase in covalency.

The ligand-field parameter $\Delta$ and the Racah parameter $B$ of $\mathrm{Cr}^{3+}$ $[8]$ and $\mathrm{Ni}^{2+}[9,10]$ ions in a number of oxidic structures have been analyzed with respect to their validity as indicators for certain properties of the metal-oxygen bond. In particular, information about the cationic environment beyond the first anionic coordination sphere of six oxygens-ligands could be obtained from the spectroscopic data: the variation of the ligand-field parameter $\Delta$ of $\mathrm{Ni}^{2+}$ ions in different 
oxidic lattices with the structure and the chemical constitution of the host lattices investigated by Reinen [9] reveals that $\Delta$ is not only a function of the $\mathrm{Ni}^{2+}-\mathrm{O}^{2-}$ distances, but is strongly influenced by polarization effects and the kind of cationic coordination of the $\mathrm{O}^{2-}$ ion as well.

No general theory is available at the present time for explaining phenomena of this kind, which are usually summarized under the term "cooperative effects".

Similar observations may be deduced from the study of optical properties of $\mathrm{Co}$ (II) direct or partially inverse spinels.

From crystallographic data, one may estimate that the increase of the ionic-covalent parameter of the trivalent associated cation in direct spinels $\left(I C P_{\mathrm{M}^{3+}}\right)$ induces an increasing effect of covalency in shortening $\mathrm{Co}^{2+}-\mathrm{O}^{2-}$ bonds. However, an opposite variation of $\Delta$ and $B$ is observed (Tab. III). A plot of the experimental values of the Racah parameter versus the ionic-covalent parameter $S_{\mathrm{Sp}}$ of the compounds $\mathrm{CoM}_{2} \mathrm{O}_{4}$ demonstrates that all the data including those for direct or partially inverse spinels fall on the same straight line (Fig. 1). The present data fit the equation:

$$
B=63.4 S_{\mathrm{Sp}}+622.3 \quad R^{2}=0.77
$$

A study of infrared reflection spectra of the II - III spinels has been undertaken [16]. The transverse and longitudinal optical phonon frequencies were determined by Kramers-Kronig analysis. It is well established that (TO-LO) $)_{1}$ of the two high-energy modes supplies a criterion of the ionicity of oxidic spinels [13, 14, 16-19]. A significant linear relationship between the (TO-LO) $)_{1}$ splittings of direct and partially inverse cobalt(II) spinels and the corresponding $S_{\mathrm{Sp}}$ is observed (Fig. 2):

$$
\Delta(\mathrm{TO}-\mathrm{LO})_{1}=114.6 S_{\mathrm{Sp}}-148.5 \quad R^{2}=0.92
$$

In conclusion, the analysis of the infrared and ligand field spectra of cobalt (II) spinels reveals that the ionicity of these compounds varies in the following order:

aluminate $>$ gallate $>$ ferrite and chromite $>$ rhodite and cobaltite. 


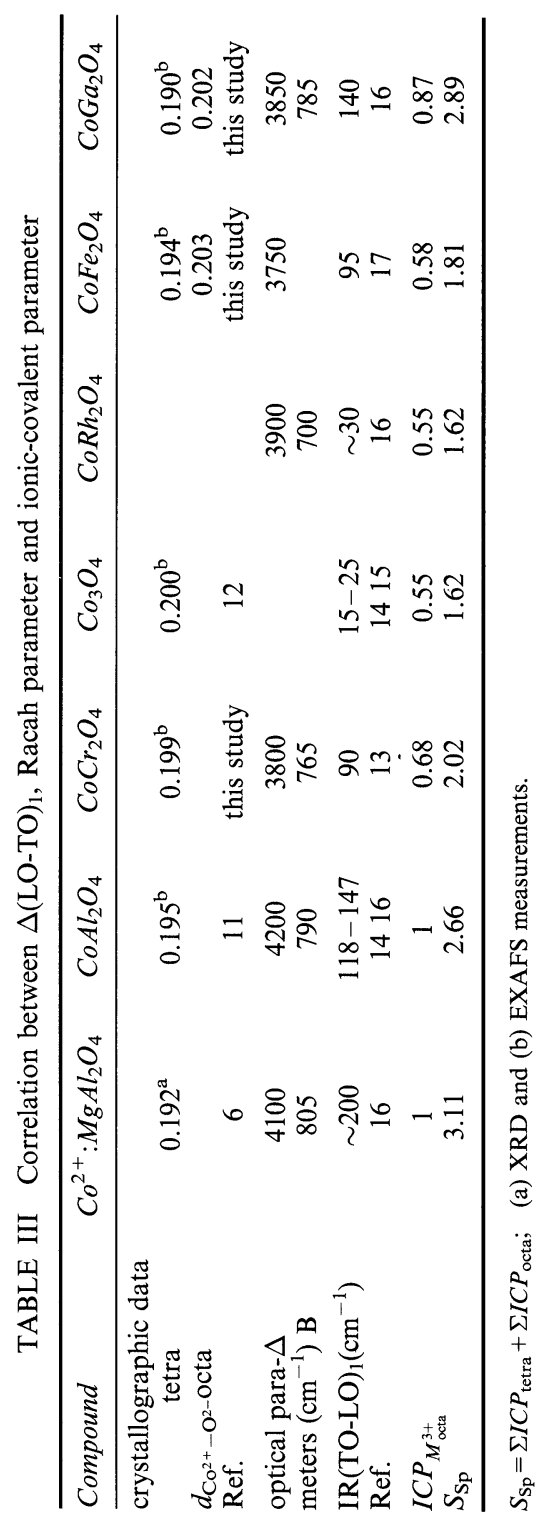




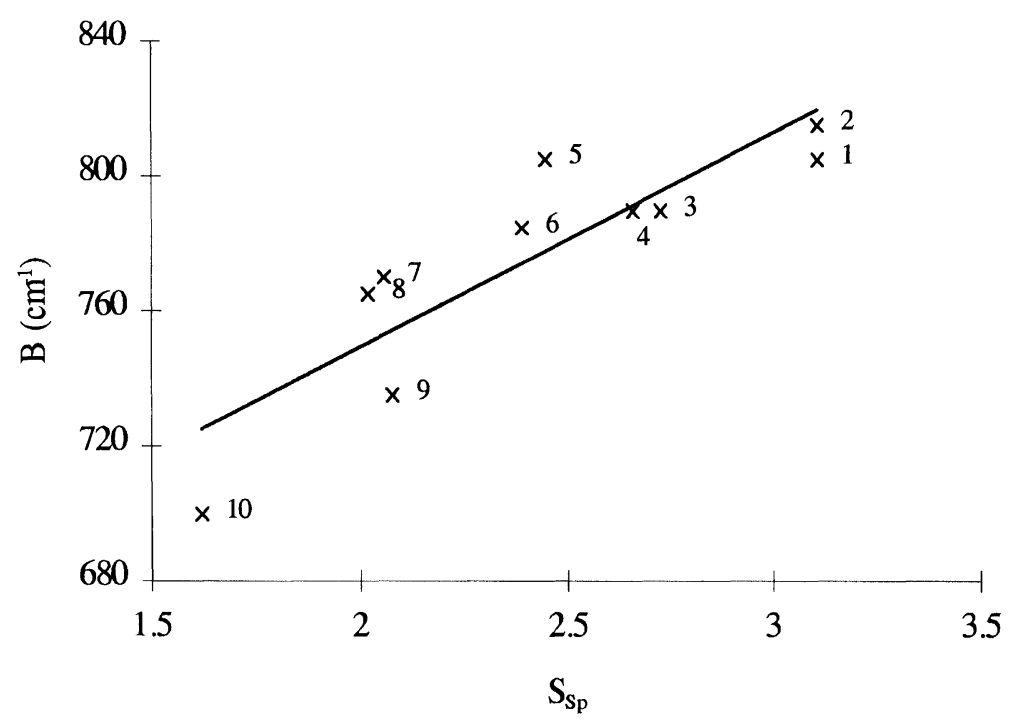

FIGURE 1 Plot of Racah parameters of $\mathrm{Co}^{2+}$ tetrahedral ions (Tab. II) as a function of $S_{\mathrm{Sp}}$.

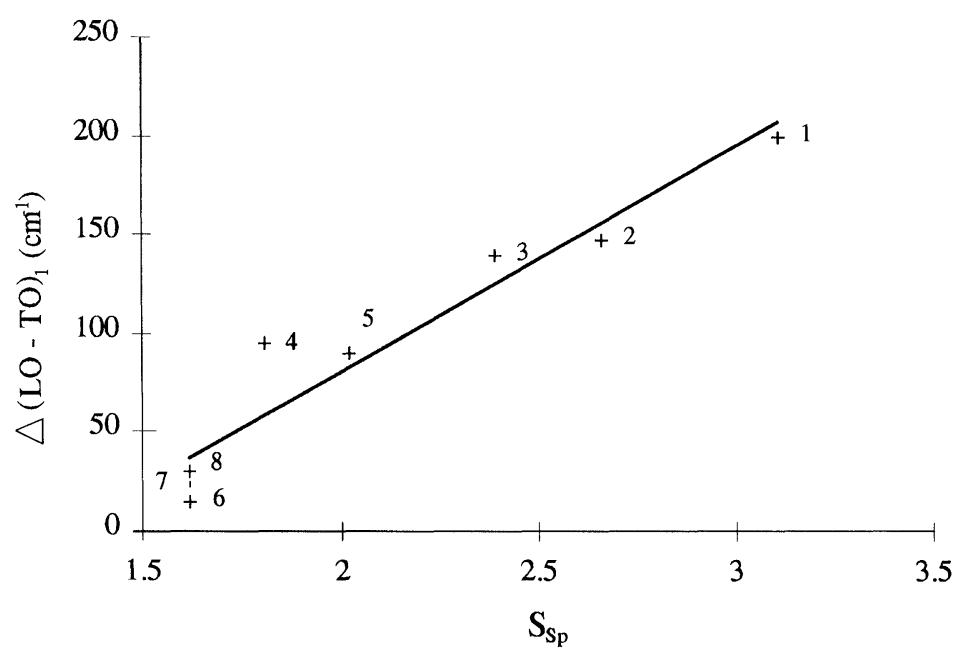

FIGURE 2 Plot $\Delta$ (TO-LO) $)_{1}$ splittings (Tab. III) of cobalt (II) spinels as a function of $S_{\mathrm{Sp}}$. 
The Racah parameter of the $\mathrm{Co}^{2+}$ tetrahedrally coordinated ion reflects the ionicity of the spinel and, consequently, is mainly influenced by the nature, the electronic configuration and spin state of the trivalent associated cation: the highest value of $B$ is observed for magnesium aluminate, i.e., in spinel formed with "hard" acids $\left(\mathrm{Mg}^{2+}\right.$, $\mathrm{Al}^{3+}$ ) and the lowest one for cobalt rhodite (the LS $\mathrm{Rh}^{3+}$ has a relatively large electronegativity). In $\mathrm{CoFe}_{2} \mathrm{O}_{4}, B$ cannot be determined because of the MMCT $\mathrm{Co}^{2+} \rightarrow \mathrm{Fe}^{3+}$ band which hides the ${ }^{4} A_{2} \rightarrow{ }^{4} T_{1}\left({ }^{4} P\right)$ transition of tetrahedral $\mathrm{Co}^{2+}$ ions (see next section). A reinvestigation of the absorption specturm of $\mathrm{Co}_{3} \mathrm{O}_{4}$ has shown that the optical transitions of this compound in the range $0.45-5 \mathrm{eV}$ are due to intense ligand field absorptions of $\mathrm{Co}^{2+}$ and $\mathrm{LS} \mathrm{Co}^{3+}$ in tetrahedral and octahedral sites and to charge transfer between $\mathrm{Co}^{2+}$ and $\mathrm{Co}^{3+}$ and from oxygen ligands to $\mathrm{Co}^{2+}$ ions [20].

\subsection{Magnetic Structure and $\mathrm{Co}^{2+} \rightarrow \mathrm{Fe}^{3+}$ Charge Transfer in Cobalt Ferrites Correlation with Magneto-Optical Properties}

\subsubsection{Fe Optical Spectra and Magnetism in Oxides}

The optical spectra of $\mathrm{Fe}^{3+}$ systems have been poorly understood. Often different ligand field states of the Tanabe-Sugano diagram are obscured by the higher energy LMCT transitions. All of the transitions of the ${ }^{6} A_{1}\left({ }^{6} S\right)$ ground state to the excited ligand field states are, in principle both spin and parity forbidden. Or, in a number of iron (III) oxides, these transitions are found instead to be quite intense: the apparent relaxation of the spin selection rule results from the magnetic coupling of next-nearest-neighbour $\mathrm{Fe}^{3+}$ cations in the crystal structure $[21,22]$. An additional phenomenon resulting from the magnetic coupling is the presence of new absorption features or pair excitations (i.e., the simultaneous excitation of two $\mathrm{Fe}^{3+}$ centers by a single photon) which are also spin-allowed and occur at energies given approximately by the sum of two single ions $\mathrm{Fe}^{3+}$ ligand field transitions [26].

The electronic structures of $\mathrm{Fe}^{3+}$ coordination sites in iron oxides have been obtained from self-consistent field $\mathrm{X} \alpha$ scattered wave (SCF$\mathrm{X} \alpha$-SW) molecular calculations on an octahedral $\left(\mathrm{FeO}_{6}\right)^{9-}$ cluster, a trigonally distorted $\left(\mathrm{FeO}_{6}\right)^{9-}$ cluster and a tetrahedral $\left(\mathrm{FeO}_{4}\right)^{5-}$ cluster [27]. Multiplet theroy has been used to relate the one-electron molecular orbital energies to the ligand field spectra of $\mathrm{Fe}^{3+}$ in 
oxides. The calculated optical spectra $\mathrm{Fe}^{3+}$ oxides summarized hereafter are compared with the experimental data relative to reference systems and have been used to interpret the NIR-Visible-UV spectra presented in Table IV.

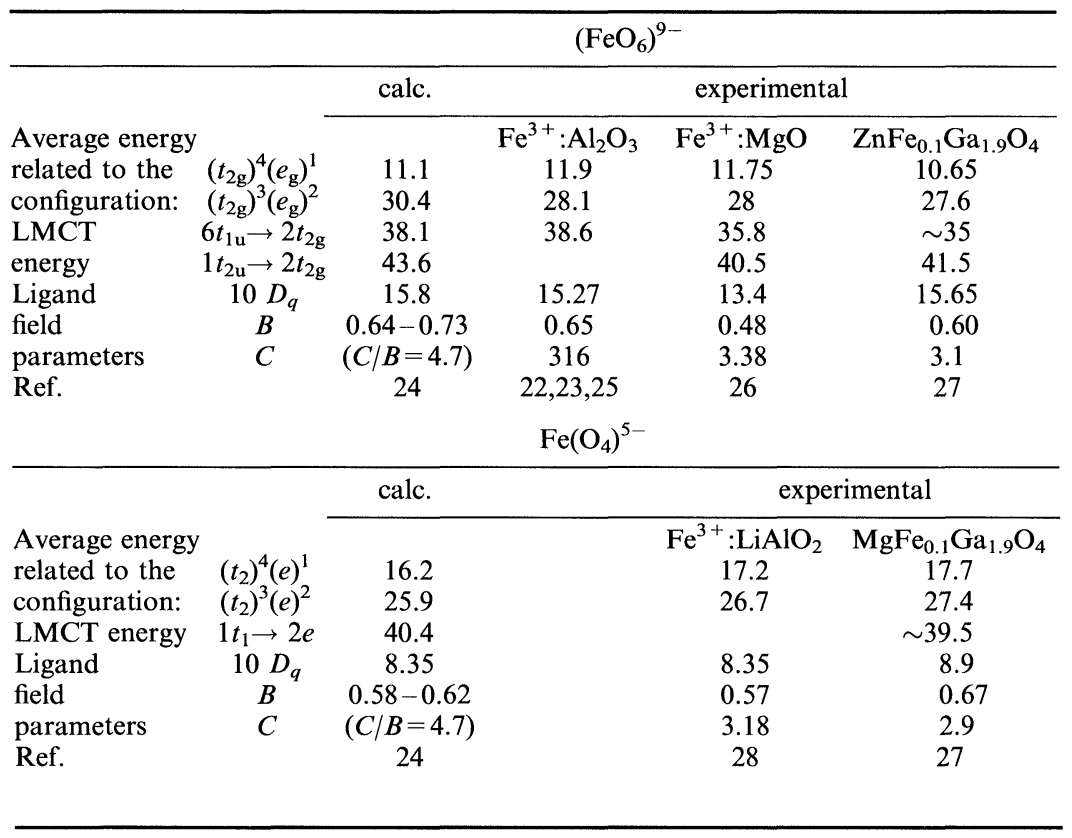

Calculated energies of the $\mathrm{Fe}^{3+}$ ligand field transitions and ligand to metal-charge transfer transitions are in good agreement with experimental data corresponding to spectra of dilute $\mathrm{Fe}^{3+}$ cations in oxide host phases. The theoretical results have been used to relate chemical bonding to the physical properties (i.e., magnetic structures) and crystal chemistry of iron (III) oxides and silicates [32, 33]. Face-sharing antiferromagnetic interactions in corundum structure and edgesharing antiferromagnetic interactions in spinel structure enhance $\mathrm{Fe}^{3+}$ ligand field transitions and $\mathrm{Fe}^{3+}-\mathrm{Fe}^{3+}$ pair transitions (both types of transitions are Laporte and spin-allowed via the magnetic coupling of adjacent $\mathrm{Fe}^{3+}$ cations). Consequently, the visible region absorption edge which gives their red or brown colors to the iron oxides does not result from LMCT transitions but is a consequence of the strong enhancement of ligand field and pair transitions. 


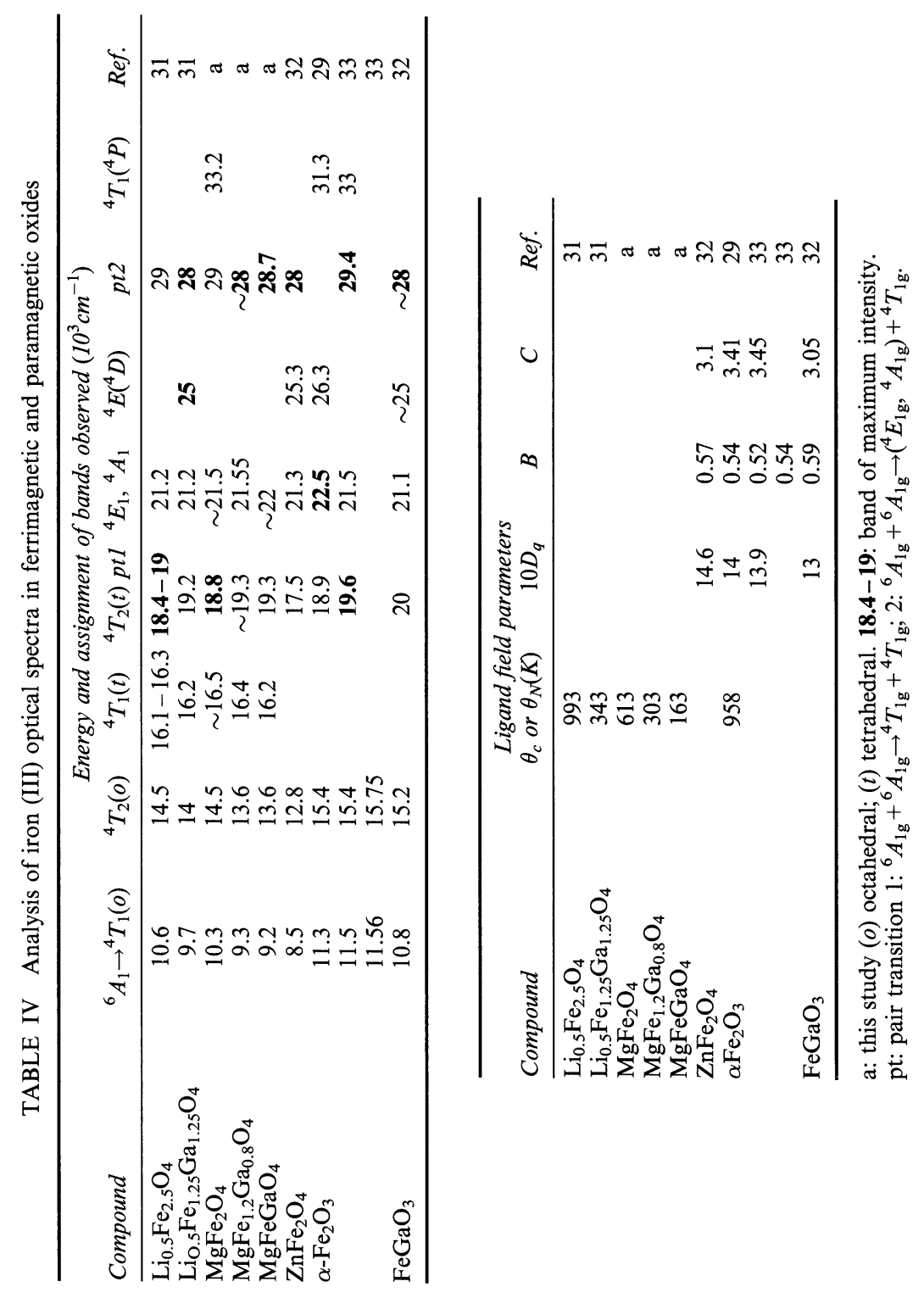


The substitution of the tetrahedral and octahedral $\mathrm{Fe}^{3+}$ by nonmagnetic $\mathrm{Ga}^{3+}$ in ferrites provides a possibility for experimentally distinguishing the different transitions (Tab. IV). In pure ferrites: $\mathrm{Li}_{0.5} \mathrm{Fe}_{2.5} \mathrm{O}_{4}, \mathrm{MgFe}_{2} \mathrm{O}_{4}$ and $\mathrm{NiFe}_{2} \mathrm{O}_{4}$, the band at $19000 \mathrm{~cm}^{-1}$ includes the ${ }^{6} A_{1} \rightarrow{ }^{4} T_{2}$ transition of the tetrahedral iron(III) and the $2\left({ }^{6} A_{1 \mathrm{~g}}\right) \rightarrow$ $2^{4} T_{1 \mathrm{~g}}\left({ }^{4} G\right)$ pair transition. The gallium substitution in these ferrites influences the nature of superexchange interactions: as the gallium content is increased, the intersublattice interactions weaken and the intrasublattice interaction become stronger facilitating a canted spin alignment on the octahedral sites. This evolution induces a considerable decrease of the $\mathrm{Fe}^{3+}$ octahedral ligand field ${ }^{4} T_{1 \mathrm{~g}}\left({ }^{4} G\right),{ }^{4} T_{2 \mathrm{~g}}\left({ }^{4} G\right)$ transitions and $2^{4} T_{1 \mathrm{~g}}\left({ }^{4} G\right)$ pair transition. Thus, the absorption edge is shifted to higher energies (i.e., from 1.5 to $2.5-3 \mathrm{eV}$ in paramagnetic compounds). The paramagnetic compounds at room temperature present a spectrum similar to that of $\mathrm{ZnFe}_{2} \mathrm{O}_{4}$ characterized by a strong intensification of the $2{ }^{6} A_{1 \mathrm{~g}} \rightarrow{ }^{4} E_{1 \mathrm{~g}},{ }^{4} A_{1 \mathrm{~g}}\left({ }^{4} G\right)+{ }^{4} T_{1 \mathrm{~g}}\left({ }^{4} G\right)$ transition in the range $28000-29000 \mathrm{~cm}^{-1}$. A similar behavior has been observed in oxides of corundum type (Tab. IV).

\subsubsection{Antiferromagnetic $\mathrm{Co}^{2+}-\mathrm{Fe}^{3+}$ Interactions and Optical Spectra of Spinel Oxides}

Figure 3 shows the absorption spectra of some cobalt ferrigallates. The spectra of the ferrimagnetic compounds are characterized by an absorption edge near $1.4 \mathrm{eV}$. The absorption edge is shifted to higher energies on the spectra of materials having a lower Curie temperature. The spectra of paramagnetic compounds are dominated by the ${ }^{4} A_{2} \rightarrow$ ${ }^{4} T_{1} \mathrm{Co}^{2+}$ transitions near 0.85 and $2 \mathrm{eV}$. The Figure 4 present the difference spectra $\mathrm{CoFe}_{2-x} \mathrm{Ga}_{x} \mathrm{O}_{4}-\mathrm{CoGa}_{2} \mathrm{O}_{4}(\mathrm{a})$ and $\mathrm{CoFe}_{2-x}$ $\mathrm{Ga}_{x} \mathrm{O}_{4}-\mathrm{MgFe}_{2-x} \mathrm{Ga}_{x} \mathrm{O}_{4}(\mathrm{~b})$. The difference spectra of ferrimagnetic materials reveal an intense band near. $1.7 \mathrm{eV}$ assigned to the $\mathrm{Co}^{2+}+$ $\mathrm{Fe}^{3+} \rightarrow \mathrm{Co}^{3+}+\mathrm{Fe}^{2+}$ metal-metal charge transfer (MMCT). This band disappears on the spectra of paramagnetic samples (Curve $E$, Fig. $4 \mathrm{a}$ and curve $C$, Fig. 4b). A tentative assignment of the different bands observed on the difference spectra is presented in Table V.

The metal-metal charge transfer involving one cloud-shell transition metal ion oxide has been thoroughly investigated but unfortunately considerably less is known about MMCT in other mixed oxides. 


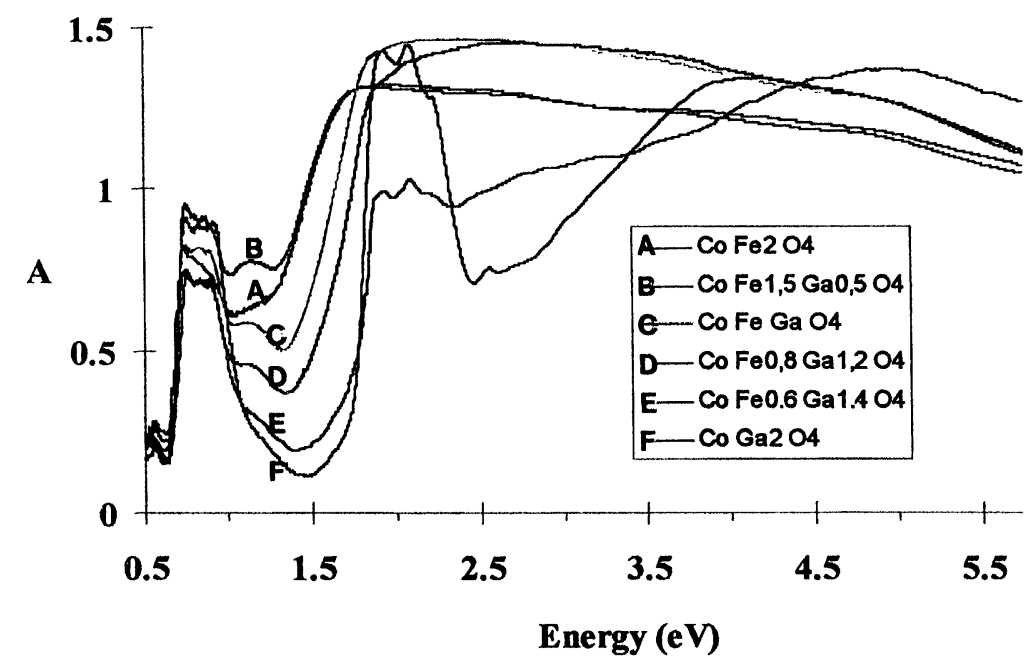

FIGURE 3 Diffuse reflectance spectra of $\mathrm{CoFe}_{2-x} \mathrm{Ga}_{x} \mathrm{O}_{4}$ solid solutions recorded at room temperature.
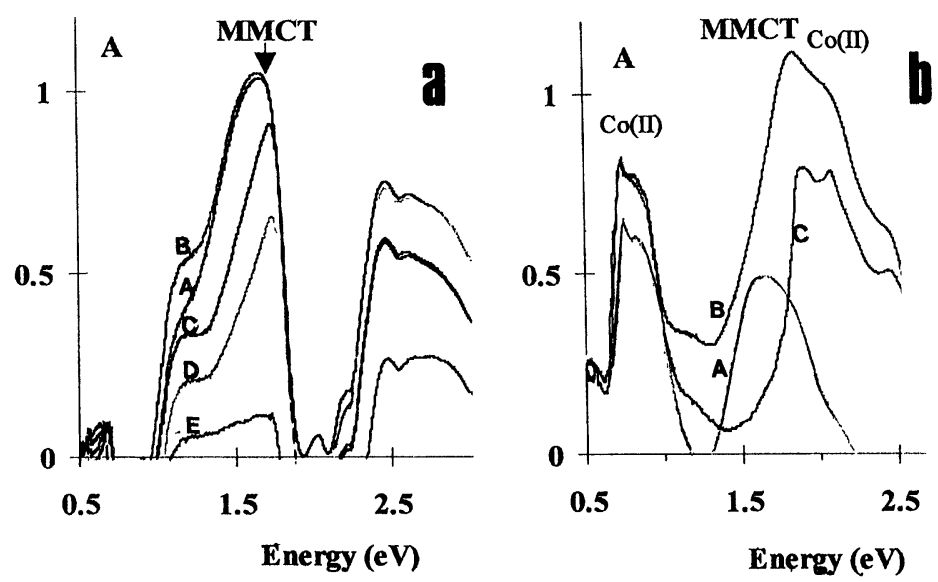

FIGURE 4 NIR-Visible difference spectra between: (a) $\mathrm{CoFe}_{2-x} \mathrm{Ga}_{x} \mathrm{O}_{4}$ and $\mathrm{CoGa}_{2} \mathrm{O}_{4}$ : (A) $x=0$; (B) $x=0.5$; (C) $x=1$; (D) $x=1.2$; (E) $x=1.4$ (b) $\mathrm{CoFe}_{2-x} \mathrm{Ga}_{x} \mathrm{O}_{4}$ and $\mathrm{MgFe}_{2-x} \mathrm{Ga}_{\mathrm{x}} \mathrm{O}_{4}$ :(A) $x=0$; (B) $x=1$; (C) $x=1.4$.

These transitions are of large importance with regards to photoredox, magneto-optical processes and are also responsible for the color of many inorganic compounds and minerals and for the presence or 


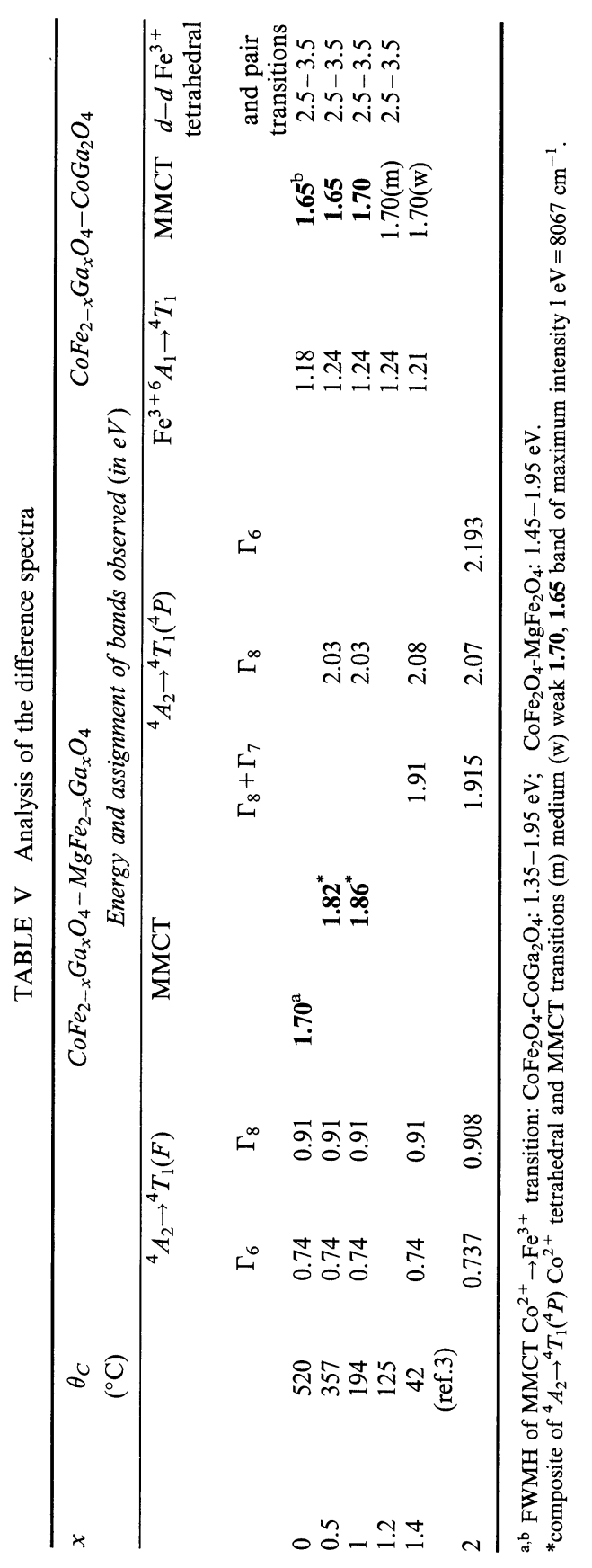


absence of certain luminescence processes. According to Blasse [34], the black color of certain ferrites like $\mathrm{MnFe}_{2} \mathrm{O}_{4}, \mathrm{CoFe}_{2} \mathrm{O}_{4}$ and $\mathrm{NiFe}_{2} \mathrm{O}_{4}$ is undoubtedly due to a MMCT of the type: $\mathrm{M}$ (II) $+\mathrm{Fe}$ (III) $\rightarrow \mathrm{M}(\mathrm{III})+\mathrm{Fe}(\mathrm{II})$ in the near infrared. The energy of the absorption for the $\left(\mathrm{MFeO}_{10}\right)^{15-}$ clusters in spinel oxides increases in the sequence $\mathrm{Fe}(\mathrm{II}), \mathrm{Co}(\mathrm{II})$ and $\mathrm{Ni}(\mathrm{II})$ as that relative to the $\mathrm{M}(\mathrm{II})+\mathrm{Ti}(\mathrm{IV}) \mathrm{MMCT}$ in $\mathrm{MgTi}_{2} \mathrm{O}_{5}$ [35]:

$$
\begin{aligned}
& \text { MMCT energy of the }\left(\mathrm{MFeO}_{10}\right)^{15-} \text { clusters (in eV) }
\end{aligned}
$$

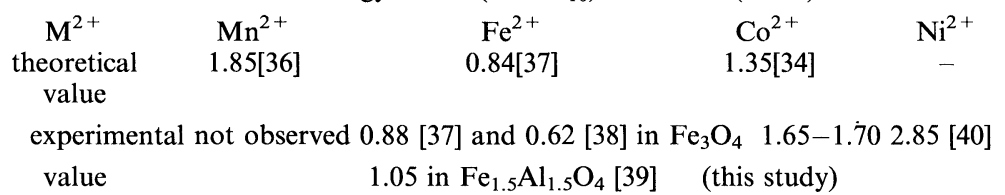

No evidence for absorption bands corresponding to possible MMCT transitions between octahedral $\mathrm{Fe}^{3+}$ and $\mathrm{Mn}^{2+}$ ions of the $\left(\mathrm{FeMnO}{ }_{10}\right)^{15-}$ cluster has been observed in minerals [39] and $\mathrm{MnGa}_{2-x} \mathrm{Fe}_{x} \mathrm{O}_{4}$ spinels.

\subsubsection{Correlation of the $\mathrm{Co}^{2+}-\mathrm{Fe}^{3+}$ Transfer and Magneto-optical Properties of Cobalt Ferrites}

The quantitative evaluation of both the charge transfer and crystal field transitions in $\mathrm{CoFe}_{2} \mathrm{O}_{4}$ and other cobalt spinels allows the interpretation of magneto-optical properties of substituted cobalt ferrites.

The magneto-optical properties of cobalt ferrites have been extensively studied [41 to 46]. The polar Kerr rotation of a $\mathrm{CoFe}_{2} \mathrm{O}_{4}$ single crystal measured in the range $0.6-5.5 \mathrm{eV}$ reveals a strong dispersive transition at $0.8 \mathrm{eV}$ and a broad transition with a dispersive transition superimposed around $2 \mathrm{eV}$. At higher energies, the polar Kerr rotation is similar to most of the iron containing spinels and garnets: the transitions at 4 and $5 \mathrm{eV}$ with a diamagnetic line shape are $\mathrm{O}^{2-}-\mathrm{Fe}^{3+}$ LMCT transitions. The transition around $0.8 \mathrm{eV}$ is identified as the ${ }^{4} A_{2} \rightarrow{ }^{4} T_{1}(F)$ transition of $\mathrm{Co}^{2+}(\mathrm{Td})$. From magneto-optical studies on $\mathrm{Al}^{3+}$ and $\mathrm{Fe}^{3+}$ substituted $\mathrm{CoFe}_{2} \mathrm{O}_{4}$, Peeters and Martens [42, 45] interpret the structure around $2 \mathrm{eV}$ as being due to two superimposed transitions: the $\mathrm{Co}^{2+} \rightarrow \mathrm{Fe}^{3+} \mathrm{MMCT}$ 


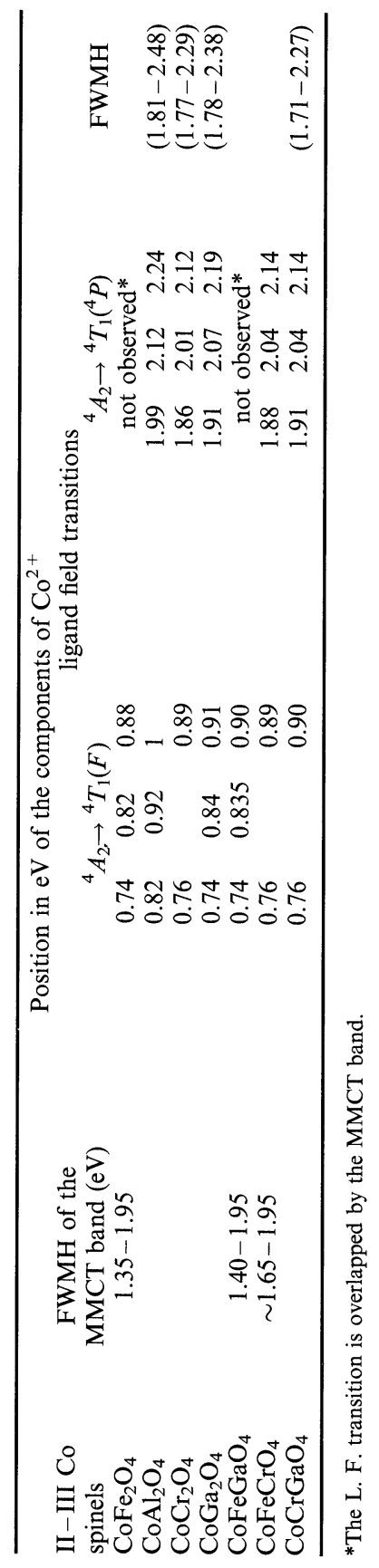


transition and the second one being the $\mathrm{Co}^{2+}(\mathrm{Td})^{4} A_{2} \rightarrow{ }^{4} T_{1}(P)$ transition with diamagnetic line shape.

The absorption coefficients and the Faraday rotation spectra of nanocrystalline cobalt ferrite thin films have been determined in the visible-near infrared range [48]. The Faraday rotation shows similar features to that observed previously [47], with two mean negative peak located near $6300 \mathrm{~cm}^{-1}(0.78 \mathrm{eV})$ and $13100 \mathrm{~cm}^{-1}(1.62 \mathrm{eV})$. Their energies are 6300 and $12500 \mathrm{~cm}^{-1}$ in ref. [47]. According to Stichauer et al. [48] the local symmetry of the ions in octahedral coordination is broken and the three symmetry point groups 4, 422 and 32 are suggested to explain the behavior of the absorption coefficient. The main features of the Faraday rotation spectra may be explained by the crystal field transitions of the $\mathrm{Co}^{2+}$ and $\mathrm{Fe}^{3+}$ ions similarly as on magnetic garnets. Influence of charge transfer cannot be disregarded around $13000 \mathrm{~cm}^{-1}$.

The experimental results issued from the study of the $\mathrm{Co}^{2+}$ optical properties in spinels allow a quantitative evaluation of the contribution of both the charge-transfer and crystal field transitions to the Faraday rotation in the range $1.5-2 \mathrm{eV}$ for different bulk samples of substituted ferrites:

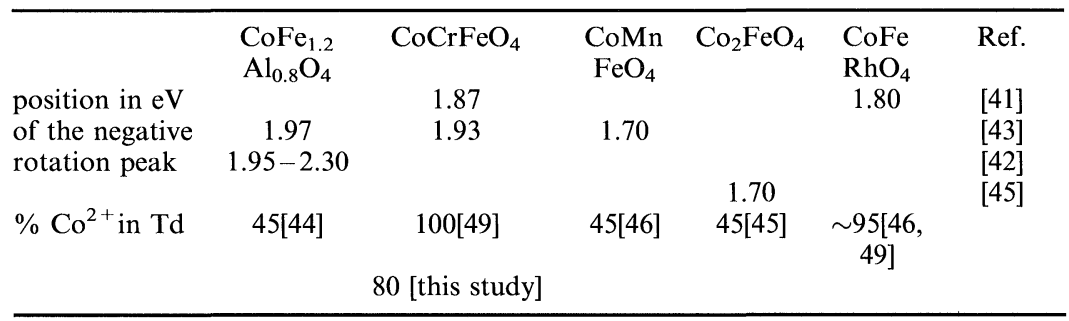

In substituted cobalt ferrites the shift of the negative peak near $2 \mathrm{eV}$ on the polar Kerr rotation spectra to higher energies may be assigned to a major contribution of the ${ }^{4} A_{2} \rightarrow{ }^{4} T_{1}(P) \mathrm{Co}^{2+}$ tetrahedral transition. The shift to lower energies as in $\mathrm{CoFe}_{2} \mathrm{O}_{4}$ and $\mathrm{CoMnFeO}_{4}$ indicates that the MMCT transition is predominating. The $\mathrm{Co}^{2+} \rightarrow$ $\mathrm{Fe}^{3+}$ MMCT energy may explain the Faraday rotations calculated Marents [46] at $1.55 \mathrm{eV}$ photon energy $(800 \mathrm{~nm})$, for various substituted $\mathrm{CoFe}_{2-x} \mathrm{M}_{x} \mathrm{O}_{4}\left(\mathrm{M}=\mathrm{Rh}^{3+}, \mathrm{Mn}^{3+}, \mathrm{Ti}^{4+}+\mathrm{Co}^{2+}\right)$. Consequently, $\mathrm{CoFe} \mathrm{RhO}_{4}$ is not a direct spinel [46] but a partially inverse one as $\mathrm{CoGaRhO}_{4}[50]$. 


\section{References}

[1] Portier, J., Campet, G., Etourneau, J., Shastry, M. C. R. and Tanguy, B. (1994). J. Alloys Comp., 209, 59.

[2] Anki, T. and Lefez, B. (1996). Appl. Optics, 35, 1399.

[3] Lensen, M. (1960). Ann. Chim. (France), 4, 891.

[4] Weakliem, H. A. (1962). J. Chem. Phys., 36, 2117.

[5] Deren, P. J., Strek, W., Oetliker, U. and Gudel, H. U. (1994). Phys. stat. Sol.(b), $182,241$.

[6] Drifford, M. and Rigny, P. (1966). C. R. Acad. Sci. (France), B263, 180.

[7] Jørgensen, C. K. (1966). Structure and Bonding, 1, 3.

[8] Reinen, D. (1969). Structure and Bonding, 6, 30.

[9] Reinen, D. (1966). Theoret. Chim. Acta, 5, 312.

[10] Reinen, D. (1971). Angew. Chem., 83, 991.

[11] Clausen, B. S., Lengeler, B., Canadia, R., Nielsen, J. A. and Topsoe, H. (1981) Bull. Soc. Chim. Belg., 90, 1249.

[12] Lenglet, M., Guillamet, R., Dürr, J., Gryffroy, D. and Vandenberghe, R. E. (1990) Solid. State Commun., 74, 1035.

[13] Lutz, H. D., Müller, B. and Steiner, H. J. (1991). J. Solid State Chem., 90, 54.

[14] Shiriai, H., Morioka, Y. and Nakagawa, I. (1982). J. Phys. Soc. Japan, 51, 592.

[15] NKeng, P., Poillerat, G., Koenig, J. F., Chartier, P., Lefez, B., Lopitaux, J. and Lenglet, M. (1995). J. Electrochem. Soc., 142, 1777.

[16] Hochu, F. and Lenglet, M., unpublished results.

[17] Lenglet, M. and Lefez, B. (1996). Solid State Comm., 98, 689.

[18] Lutz, H. D., Wäschenbach, G., Kliche, G. and Haeuseler, H. (1983). J. Solid State Chem., 48, 196.

[19] Katsnelson, E. Z., Karosola, A. G., Meleshchenko, L. A. and Bashkirov, L. A. (1989). Phys. Stat. Sol. (b)., 152, 657.

[20] Lenglet, M. and Jørgensen, C. K. (1994). Chem. Phys. Letters, 229, 616.

[21] Lohr, L. L. (1972). Coord. Chem. Rev., 8, 241.

[22] Krebs, J. J. and Maisch, W. G. (1971). Phys. Rev., B4, 757.

[23] Ferguson, J. and Fielding, P. E. (1972). Austr. J. Chem., 25, 1371.

[24] Sherman, D. M. (1985). Phys. Chem. Minerals, 12, 161.

[25] Lehman, G. and Harder, H. (1970). Am. Mineral, 55, 98.

[26] Blazey, K. W. (1977). J. Phys. Chem. Solids, 38, 671.

[27] Lenlget, M., Bizi, M. and Jørgensen, C. K. (1990). J. Solid State Chem., 86, 82.

[28] Waychunas, G. A. and Rossman, G. R. (1983). Phys. Chem. Minerals, 9, 212.

[29] Sherman, D. M. and Waite, T. D. (1985). Am. Miner., 70, 1262.

[30] Sherman, D. M. (1985). Phys. Chem. Minerals, $12,311$.

[31] Hochu, F., Lenglet, M. and Jørgensen, C. K. (1995). J. Solid State Chem., 120, 244.

[32] Lenglet, M., Hochu, F. and Music, S. (1995). Solid State Commun., 94, 211.

[33] Music, S., Lenglet, M., Popovic, S., Hannoyer, B., Czako-Nagy, I., Ristic, M., Balzar, D. and Gashi, F. (1996). J. Mat. Sci., 31, 4067

[34] Blasse, G. (1991). Structure and Bonding, 76, 153.

[35] Blasse, G. and Dirksen, G. J. (1981). Chem. Phys. Letters, 77, 9.

[36] Sherman, D. M. (1990). Am. Mineral., 75, 256.

[37] Sherman, D. M. (1987). Phys. Chem. Minerals, 14, 355.

[38] Feil, H. (1989). Solid State Commun., 69, 245.

[39] Lenglet, M., Arsene, J. and Jeannot, F. (1987). Rev. Chim. Min., 24, 81.

[40] Lenglet, M. and Jørgensen, C. K. (1992). Chem. Phys. Letters, 197, 259

[41] Ahrenkiel, R. and Coburn, T. (1975). IEEE Trans. Magn. Mag., 11, 1103.

[42] Peeters, W. L. and Martens, J. W. D. (1982). J. Appl. Phys., 53, 8178.

[43] Abe, M. and Gomi, M. (1982). J. Appl. Phys., 53, 8172. 
[44] Martens, J. W. D., Peeters, W. L., Nederpel, P. Q. J. and Erman, M. (1984). J. Appl. Phys., 55, 1100.

[45] Martens, J. W. D., Peeters, W. L., Van Noort, H. M. and Erman, M. (1984). J. Phys. Chem. Solids, 46, 411.

[46] Martens, J. W. D. and Voermans, A. B. (1984). IEEE Trans. Magn. Mag., 20, 1007.

[47] Suzuki, K., Namikawa, T. and Yamazaki, T. (1988). Japan J. Appl. Phys., 27, 361.

[48] Stichauer, L., Gavoille, G. and Simsa, Z. (1996). J. Appl. Phys., 79, 3645.

[49] Blasse, G. (1964). Philips. Res. Rep. Suppl., nº 3.

[50] Porta, P., Anchini, A. and Guglieti, A. (1983). Gazetta Chim. Ital., 113, 595. 

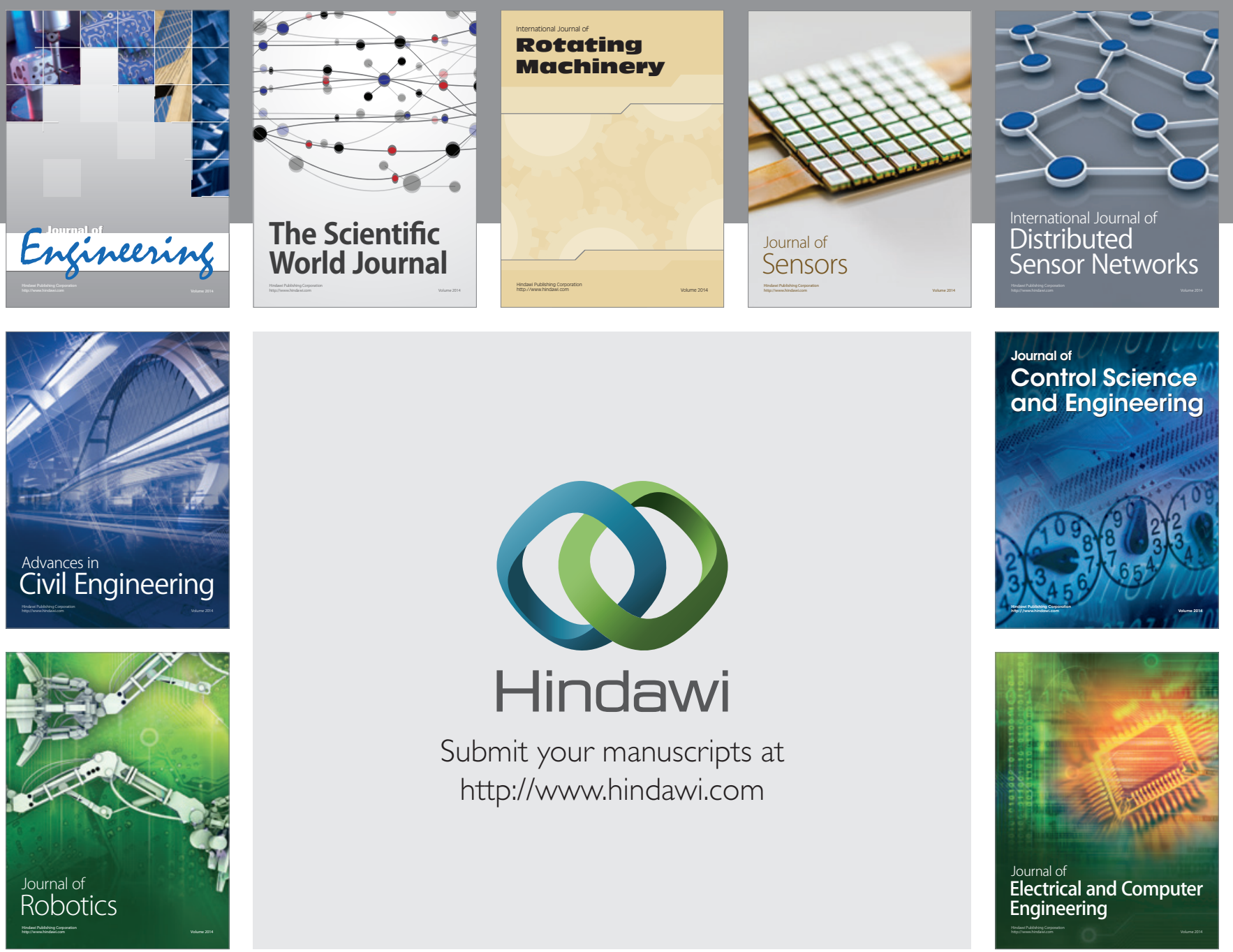

Submit your manuscripts at

http://www.hindawi.com
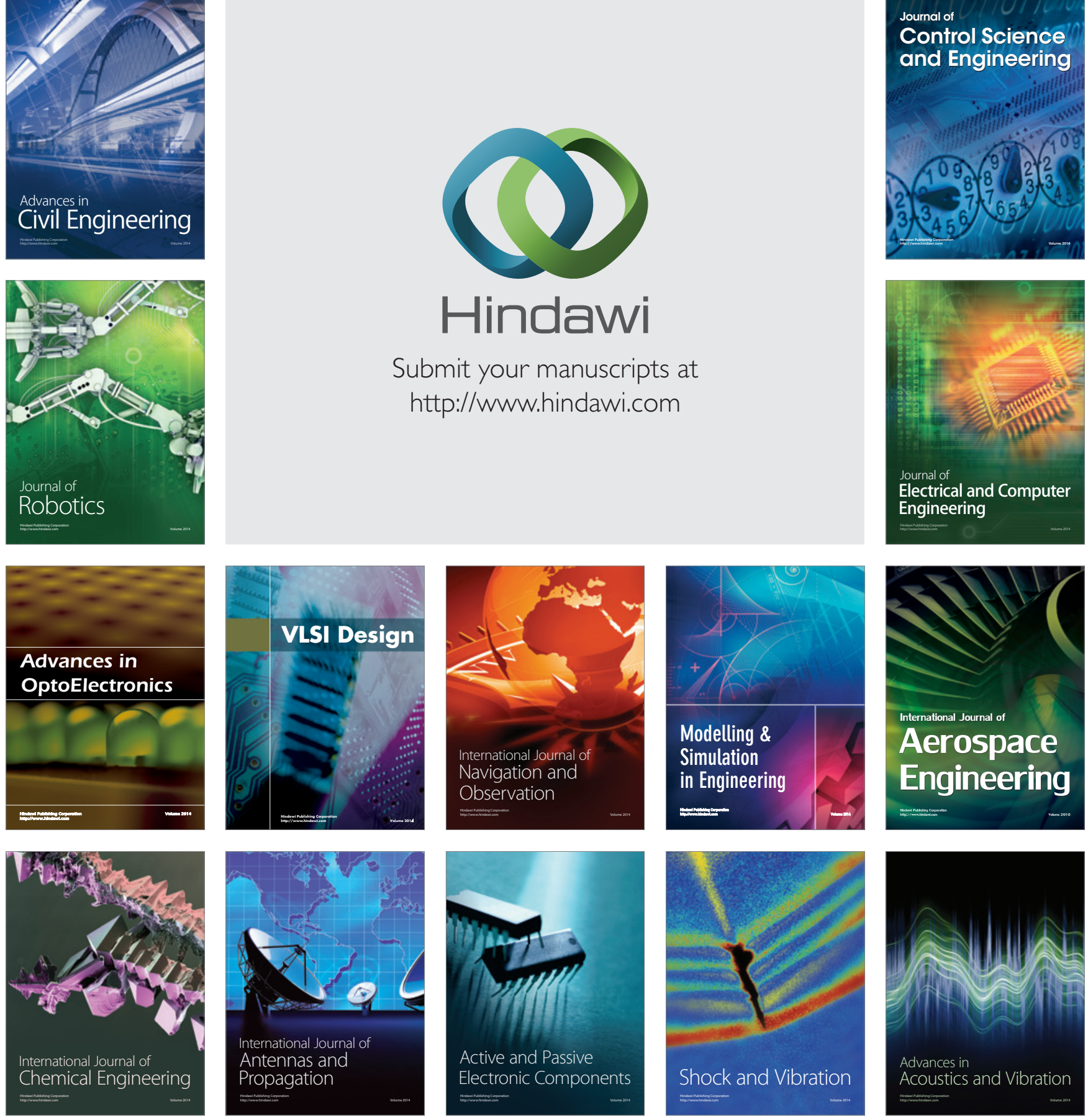